\title{
Българското поколение билингви в Унгария
}

\author{
Мария Жерева \\ (София, България)
}

Българската диаспора в Унгария е разнородна. Установено е, че има три преселнически вълни на българи към Унгария. Тук няма да се спирам на историческите факти и условия, тъй като изследването ми се отнася за последното българско поколение билингви, деца от смесени бракове или потомци на старите преселници.

Отношението на българите от диаспората към родината майка и родния език е различно и то се променя със смяната на поколенията. За историческата диаспора, за нейната история, за сегашното й състояние и развитие има многобройна литература.

За поколението билингви все по-често се говори и пише в ерата на глобализацията. Хората пътуват, сменят местожителство, намират си партньори от други страни.

Билингвизмът е разглеждан като социално, психологическо и лингвистично явление. Изучаван и описван от социолингвисти, етнолингвисти, психолози, от гледна точка на чуждоезиковото обучение, билингвизмът има много нюанси, но това не изменя дефиницията му. Тук приемаме твърдението на Хогън, че билингвите разполагат с повече от една езикови системи, но това не означава, че владеят и двете еднакво или перфектно на всички езикови нива. ${ }^{1}$ Билингвалният индивид има достатъчна минимална компетенция по втория език, за да направи смислено завършено изказване на този език. Изискването за това е индивидът да е живял в условията на билингвална среда. Или, както твърди Вайнрайх, условие за билингвизъм е контактът с два езика. ${ }^{2}$

1 HAUGAN, E.: Blessings of Babel. Bilingualism and Language planning. Moutonde Gruyter. Berlin-New York-Amsterdam, 1987, s. 3.

2 VAJNRAJCH, U.: fazykovyje kontakty. Kijev, 1979, s. 1. 
Не можем да оставим без внимание и мнението на Адлер, че не само езикът, но и културата на другата група е в основата на понятието билингвизъм. ${ }^{3}$

В научната литература се говори за няколко вида билингвизъм: вроден (ранен), когато детето се учи едновременно на базовия и на чуждия за него език и придобит (късен), билингвизъм, когато човек започва да усвоява чужд език, след като вече е сформирал навици да общува на своя роден език. Още може да се говори за естествен и изкуствен билингвизъм. Естественият билингвизъм се формира при необходимост да се говори на два езика с цел следване в университет, работа, смесен брак и др. Изкуственият билингвизъм е при човек, който изучава чужд език, но в ежедневието си не го използва регулярно. В изследването ми става дума за вроден (ранен) естествен билингвизъм.

Разбира се, при смесен брак, когато е налице билингвална обстановка, установяването на майчиния език е по-трудно и затова тук приемаме мнението на Скутнаб-Кангас и терминологията на М. Виденов, за която ще стане дума по-долу.

Освен билингвизъм, в научната литература съществува и понятието диглосия. За разлика от билингвизма, диглосията е понятие, с което специалистите означават „владеенето на повече от една форма на съществуване на един и същ език... В състояние на диглосия, например е всеки, който освен книжовния език владее и някакъв традиционен териториален диалект“. 4 За такъв билингвизъм може да се говори при най-старите преселници, които идват от българските села, главно от района на Велико Търново.

По отношение на понятията роден и чужд език също има различни мнения, но за нуждите на изследването си приемам становището на проф. Михаил Виденов, според когото езикът на семейството (или така наречената първична група), където се социализира индивидът, може да се индентифицира като роден: „Чужд за индивида е езикът, различен от този на първичната група, в която протича социализацията“. 5 Разбира се, понятията роден и чужд език не могат да са адекватни в многообразието от случаите в речевата практика. Ето защо тук тези термини приемаме за условни и предпочитаме термините първи и втори език (по степен на владеене или по важност в социалната комуникация).

Изследванията на психолози и лингвисти показват, че в ранното си детство детето с лекота усвоява два езика, тъй като това става с помощта на един

3 ADLER, P.: Culture Shock and the Gross Cultural Learning. Experience. Readings in international Education, vol. 2, 1972, s. 9.

4 VIDENOV, M.: Uvod v sociolingvistikata. Sofija, 2000, s. 208.

5 Ibidem. 
и същ механизъм в мозъка. Езиковата способност на човека не се влияе от това какъв и колко езика усвоява детето. Напротив, езиковата способност на всеки човек позволява той да бъде двуезичен. Мисленето на детето билингва става понятийно по-богато. Информацията, чута на единия език от билингва може да бъде възпроизведена на втория език, при условие, че е разбрана. Трудностите във възпроизвеждането на информацията на един език могат да бъдат само лексикални.

Между езикова и комуникативна компетентност има разлика. Езиковата компетентност означава различаване на даден езиков код, докато комуникативната компетентност изисква и екстралингвистични познания. Комуникативната компетентност е съвкупност от определени социални, лингвистични и социолингвистични фактори и се основава на езикова компетенция, социолингвистична компетенция и възможност за осъществяване на комуникативен дискурс.

За двуезичен или билингва може да се определи човек, който повече или по-малко постоянно използва в живота два езика. Точно многоезичието е вече норма в изменената и изменяща се Европа.

Според това, кога става усвояването на втория език, може да се говори за ранен и късен билингвизъм. Различава се също репродуктивен (възпроизвеждащ) и продуктивен (произвеждащ) билингвизъм.

При смесените бракове обикновено децата са билингва, но само при условие, че и двамата родители разговарят с детето на своя роден език. Колкото по-късно в общуването с детето се въвежда втория език, толкова повече първият език доминира над втория. Т. е. колкото по-рано у детето се оформят лингвистични системи, толкова по-рано то ще може да мисли на двата езика.

Децата от смесени бракове в Унгария от ранно детство се научават да говорят унгарски език, поради социалната среда, в която живеят - унгарски роднини, детски дом, унгарски приятелчета. Те даже мислят на унгарски. Но, ако единият родител, който е българин, му говори на български, детето започва свободно да отговаря на български, да разбира и да го говори свободно. В повечето случаи, обаче, не може да пише на български език. Това е така, защото говорът се овладява произволно в процеса на естественото общуване на подрастващите, а четенето и писането са резултат на съзнателно и организирано обучение.

При условие, че детето е научило и двата езика до 3-4 годишна възраст, може да се говори за едновременен (симултанен) билингвизъм, каквито случаи са регистрирани при изследването. Усвояването на български език след 3-4 годишна възраст вече дава основание да се говори за последователен билингвизъм. Въпреки че и двата езика са научени по едно и също време, 
компетенцията по двата езика никога не се оказва еднаква. Винаги унгарският език е доминантен, а българският - доминиран.

В научната литература се говори за координативен или симетричен билингвизъм, ${ }^{6}$ когато двата езика се говорят и използват на еднакво ниво. За асиметричен билингвизъм може да се говори, когато единият език е доминант, т. е. обслужва повечето ситуации, а другият само се разбира или се говори слабо. Освен това билингвизмът може да бъде пълен (когато двете системи са овладени добре и при комуникация едната система не влияе на другата) и непълен (когато говорещият владее добре единия език, но не владее добре другия и при общуването прави чести заемки от първия език).

Изследваните индивиди от младото днешно поколение от смесен брак в Унгария могат да се определят като асиметричен и непълен тип билингви, според терминологията на Пиаже ${ }^{7}$ като при тях по-слаб е българският език.

Тези деца се сблъскват с определени трудности, свързани главно с въпроса за функционирането на втория език (в случая български), който независимо, че се ползва, в идеалния случай редом с първия език (унгарски), все пак остава подчинен на него, особено ако се налага повече креативно мислене. Нещо повече, в социолингвистиката съществува понятието „отнемащ билингвизъм“, който интерпретира случаите, когато човек избягва определени ситуации, тъй като вторият език (в случая български) ще му „отнеме“ езика на социума, в който живее. Във втория език се вижда заплаха за първия. Това се наблюдава и в поколението билингви в Унгария. Една девойка с майка българка и баща унгарец ми каза, че не иска да говори много на български, защото така ще свикне и ще забрави унгарски. Това шоково за мене твърдение намира потвърждение в научната литература. Всъщност, човек се приспособява към средата, в която се намира.

Докато до средата на 50-те години на XX век българите в Унгария са говорели и двата езика, но предимно български и са възпитавани в българска среда, то в наши дни вече преобладава екзогамното семейство, при което единият член е унгарец. Това предполага, че поколението е родено и възпитавано в унгарска среда и говори и двата езика, но предимно унгарски. Върху това поколение определящо въздействие върху ценностната му ориентация, начин на мислене и поведение е оказал унгарският модел.

Общуването в многоезичните съобщества често зависи от това, кой с кого на каква тема и в какви условия говори. Билингвалните семейства се отнасят

6 BEL, R.: Sociolingvistika. In: Meždunarodnyje otnošenija, 1980, s. 157.

7 PIAŽE, Ž.: Psichologija intellekta. In: Izbranyje psichologičeskije trudy. Moskva, 1994. 
към този тип съобщества. Ф.Гросжан ${ }^{8}$ изказва мнението, че в зависимост от езиковите умения на събеседниците, техните взаимоотношения, навици за смесване на езиците превключване на кода, при комуникацията може да се променя количеството на единия или другия език. Функциите на речевия акт може да изменят езиковия модус.

При анализа на речта на унгарски двуезични индивиди от смесен брак най-често се наблюдава смесване на езиците в едно изречение, например: Аз не говоря български на профисинт (професионално ниво), Не знам какво е работил тогава, но знам, че е бил и партиткар (партиен секретар), Харесвам цвят тъмнокейк (тъмносиньо), В нашето полгар ишкола (градско училище) учим руски език, Хат (ами) той купи нова кочия (кола), Много обичам месо в капуста (зеле), Аз тук много обичам да ям тепертьо (пръжки), ама в България не харесвам да ям това, Тя е в ирода (канцеларията) и сега идва, Завърших зене ишкола (музикално училище), Следвам газдашаг (икономика) и др.

За разлика от старото поколение на българските градинари, младото българско поколение билингви в Унгария са носители на книжовен български, тъй като българските им родители са обикновено добре образовани, завършили са висшето си образование в България, а и те имат близки роднини в България, с които говорят на български език. Но, все пак това ново поколоние живее, учи, работи в Унгария и българският им език има „свидетелства“ за живота им в унгарска езикова среда, които могат да са с по-малка или по-голяма честота. Например, регистрирана е промяна на словореда под влияние на унгарски синтактични модели като Подадох молба че да уча руски, Затова ми е лесно, защото знам руски, Затова няма да идвам, защото съм болен, Чакам Имре бачи (Чичо Имре) и веднага щзе дойда, Питай Аги нене (леля Аги) и др. Често се среща използване на унгарския вариант на фонемата $\mathrm{X}-y u u(x), x о д u(x)$, използаване на унгарски предложни конструкции като Чy(x) това в радиото, вместо ...по радиото, по-лесно е на мен да говоря унгарски, вместо ...за мен, На училището учих руски език, вместо ...В училище... и др.

Превключването на кода като явление, присъщо на билингвизма е характерно за всички двуезични индивиди. Според Гросжан ${ }^{9}$ това превключване на кодове включва трансфер на думи, фрази и дори изречения от един език на друг. Но трансферирането на думи, фонеми и морфеми е по-скоро интерференция, отколкото чисто превключване на кода. Според Вайнрайх интерференция може да се наблюдава както в речта, така и в езика. В поколението български

8 GROSJEAN, F.: Bilingual and monolingual modes. In: CHAPELLE, C. A. (ed.): The Encyclopedia of Applied Linguistics, New York: Blackwell, 2013.

9 GROSJEAN, F.: An introduction to Bilingualism. Harvard University Press, 1982, s. 145 - 157. 
билингви в Унгария се наблюдава интереференция от унгарски както в акцента и произношението, така и в синтактични модели, характерни за унгарски език.

Анализът показа, че най-честата интерференция е от унгарски на български език, но има и случаи на интерференция при различни езикови равнища. Проникването на чужди елементи от единия или другия език може да се обясни не само с резистентност на дадено езиково равнище, но и с естеството на междуезиковия контакт. На различните езикови равнища се откриват различно количество интерференции. Например, крумплите (картофите) сега cтруват скъпо. Интерференциите на ниво формална морфология се дължат на придобиване на граматична компетенция по втория език (българския). Думата крумпли е унгарска, но определителният член е български. Примерът показва, че е възможно както трансферирането на словообразувателни елементи (афикси и суфикси), така и пренасяне на словообразувателни модели от български на унгарски или обратно. Така могат да се обяснят някои лексикални новообразувания, открити в речта на унгарските билингви като подспис, (послепис), ръчнопис (ръкопис), хубавелирам, (разхубавявам), розвирааг (цвете роза) халсупа (рибена супа), едното ми ухо е залегнало (запушено), Ще си направя (отделя) време, Слушах хубаво зене (музика) и др. Тъй като обикновено говорещият определя рода на съществителното, което употребява по крайната гласна Е за среден род, то и към него се приспособява граматически и прилагателното хубаво. Това, разбира се има и изключения. Много по-често се откриват думи, които изискват промяна в морфемния строеж на думата, но такава промяна не е направена, т. е. думата е запазена в унгарския си вариант, без да е модифицирана. Такъв е случаят с употребата на членната форма - Показваш картя (картата) и влизаш, Идвам като изчистя локаша (локаш - апартамент, плюс българския определителен член), Това е жидовският (еврейският) квартал и др.

Друг вид адаптация е приспособяването на българска дума към унгарската граматична система и неправилното ѝ използване с различен граматичен род като Тук има един програм на фестивала, Това е етникаи (етнически) въпрос.

При поколението билингви в Унгария се наблюдават най-общо казано три типа грешки при употреба на български език - лошо произнасяне на фразите, нарушаване на граматическите правила и грешки в подбора на думите. Тези грешки в някои случаи се осъзнават от говорещия, но в други случаи - не се осъзнават.

Всъщност, българският език на младото билингва поколение в Унгария се променя с бързи темпове, но в основата му е желанието на семейството да възпита билингва дете. Граматичната система, заложена в съзнанието на 
индивида не е установена и постоянна, а непрекъснато е подложена на влияния и промени. Двете езикови системи на български и унгарски се смесват или даже взаимно се заместват, без говорещият да забележи това. При някои от анкетираните респонденти се наблюдава по-голямо влияние на първия език върху втория и то най-често на равнище лексикология. Това се оказва найпропускливата област. Морфологията е по-устойчива откъм интерференции, а навлизането на интерференция на морфологично ниво може да доведе до трайно разбиване на езиковата система на единия език.

Интересът кам българските общности в чужбина във все по-глобализиращия се свят става все по-голям. Социолингвистичните изследвания дават реална представа за това доколко е жив българския език в общностите в чужбина. Езикът е елемент от културата, който идентифицира носителите му и ги причислява към дадена общност. Запазването на българския език в чужбина е най-мощното средство срещу асимилацията.

\section{Литература:}

ADLER, P.: Culture Shock and the Gross Cultural Learning. Experience. Readings in international Education, vol. 2, 1972.

ANGELOV,B.: Ovladjavaneto na ezika meždu individualnostta i bilingvizma. Sp. Pedagogika, br. 1, 2001.

BEL, R.: Sociolingvistika. In: Meždunarodnyje otnošenija, 1980.

GROSJEAN, F.: An introduction to Bilingualism. Harvard University Press, 1982.

GROSJEAN, F.: Bilingual and monolingual modes. In: CHAPELLE, C. A. (ed.): The Encyclopedia of Applied Linguistics. New York: Blackwell, 2013.

GROSJEAN, F.: Life with two languages. Cambridge, MA: Harvard University Press, 2010.

HAUGAN, E.: Blessings of Babel. Bilingualism and Language planning. Moutonde Gruyter. Berlin-New York-Amsterdam, 1987.

HAUGAN, E.: Minority Languages in Europe. Frameworks, 2003.

PIAŽE, Ž.: Psichologija intellekta. In: Izbranyje psichologičeskije trudy. Moskva, 1994. SKUTNAB-KANGAS, T.: Linguistic Genocide in Education-or Worldwide Diversity and Human Rights? Mahwah. NY L. Erlbaum Associates, 2000.

SKUTNAB-KANGAS, T.: Linguistic Human Rights: Overcoming Linguistic Discrimination. New York, M. De Gruyter, 1995.

VAJNRAJCH, U.: Jazykovyje kontakty. Kijev, 1979.

VIDENOV, M.: Uvod v sociolingvistikata. Sofija, 2000. 


\section{About the author}

\section{Mariia Zhereva}

Sofia University “St. Kliment Ohridski”, Faculty of Slavic Studies, Department

for Language Teaching, Sofia, Bulgaria

mzhereva@abv.bg 